\title{
Introduction to the Nitrate in Groundwater papers
}

\author{
Daren C Gooddy ${ }^{1}$ \& Tim Besien ${ }^{2}$ \\ ${ }^{1}$ British Geological Survey, Wallingford, UK \\ ${ }^{2}$ Environment Agency, UK
}

Escalating concentrations of nitrate in groundwater supplies resulting from major changes in post-WWII agricultural production were first widely recognised in the 1970s, prompting discussion on the 'nitrate time-bomb' problem. The implications of this problem are now becoming clear with increasing numbers of water company groundwater abstractions needing expensive and energy intensive treatment.

Since the 1970s, considerable research effort has been directed towards understanding and predicting nitrate pollution in groundwater. This research has concluded that measures to address the nitrate problem, particularly in England, have largely failed. This has prompted a growing feeling in the UK's hydrogeological community that we need to make a step change in our approaches to protecting groundwater from all sources of nitrate including nonagricultural sources.

In addition, the UK is currently implementing the Water Framework Directive, which is intensifying interest among water suppliers, regulators, and NGOs in the groundwater nitrate problem. Consequently, the Hydrogeological Group of the Geological Society elected to organise a one-day meeting on the subject at Burlington House, under the title "Nitrate in groundwater: Past trends and future challenges". The objective of the meeting was to take stock of our state of knowledge after more than 30 years of intensive research into the transport and residence of nitrate in UK groundwater systems and to assess where we should go from here.

The meeting took place on February $6^{\text {th }} 2007$ with 17 speakers, and 170 delegates from academia, the Environment Agency, the National Farmers Union, Natural England and a considerable number of environmental consultants. The conveners captured a broad range of aspects of nitrate in groundwater including regulatory policy, the perspectives of the water companies and recent research findings. More specifically, papers covered nitrate movement through unsaturated and saturated zones, attenuation through the hyporheic zone, modelling of trends, isotopic tracers as source indicators, methods for designating Nitrate Vulnerable Zones, and possible palliative measures to reduce the impact of nitrate on groundwater quality.

This thematic set of papers has been selected from those presented at the meeting in order to represent the range of topics covered. The conveners of the meeting would like to thank the participants, particularly those who contributed to a lively debate, the presenters, especially those who were able to produce full manuscripts to a very tight deadline, and the Editorial Board of the Quarterly Journal of Engineering Geology and Hydrogeology for providing an appropriate outlet for this set of papers to be published. 